\title{
Selection of an Optimal Supplier
}

\author{
Predrag Ćosić ${ }^{*}$ Zdenka Keran, Vedran Kokot
}

\begin{abstract}
The paper describes the selection of an optimal supplier from China based on three obtained bids to produce 120000 forged pieces, which is the primary process for shaft production. The choice was made using the AHP method based on the Expert Choice software program and Multiple-Criteria Decision-Making (MCDM). The key information when choosing the optimal supplier of large number of forgings is to define the objective of the task, decision tree with weighted criteria and sub-criteria, consistency checking and possible reconsideration using brain storming when defining the strength of criteria/sub-criteria. To some extent, this may reduce initial subjectivity in the decision-making process in the Decision Support System.
\end{abstract}

Keywords: Analytical Hierarchy Process (AHP); Multiple-Criteria Decision-Making (MCDM); optimization of selection optimal supplier

\section{INTRODUCTION}

Choosing the primary forging process as the best between the potential processes - forging, extrusion or casting - was the initial step towards the idea of choosing the optimal shaft supplier between three forges in PR China. A Chinese forge made three offers to produce 120000 forgings. The comparison and final selection of the optimal offer was made depending on the criteria and sub-criteria. Defining and weighting of criteria and sub-criteria was the key to defining decision tree and AHP models. The selection of the optimum primary process as well as the selection of the optimum supplier was done by using the Expert Choice 11 software program based on the AHP method.

Table 1 Materials, number per year, manufacturing process and relative cost [5]

\begin{tabular}{|c|c|c|c|c|c|}
\hline Component & Material & Number Per Year & Manufacturing Process & Relative Economic and Technical Merits & Relative Cost \\
\hline \multirow{2}{*}{ Plug Body } & \multirow{2}{*}{$\begin{array}{l}\text { Low Carbon } \\
\text { Steel }\end{array}$} & \multirow{2}{*}{1000000} & Machining & $\begin{array}{l}\text { High waste } \\
\text { Low to medium production rates } \\
\text { Poor strength }\end{array}$ & 3.9 \\
\hline & & & Cold Forming & $\begin{array}{l}\text { Little waste } \\
\text { Very high production rates } \\
\text { High strength }\end{array}$ & 1.0 \\
\hline \multirow{2}{*}{ 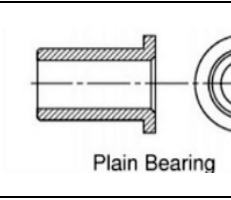 } & \multirow{2}{*}{ Bronze } & \multirow{2}{*}{50000} & Machining & $\begin{array}{l}\text { High waste } \\
\text { Low to medium production rates } \\
\text { Non-porous product properties } \\
\end{array}$ & 2.2 \\
\hline & & & Powder Metal Sintering & $\begin{array}{l}\text { No waste } \\
\text { High production rates } \\
\text { Porous product }\end{array}$ & 1 \\
\hline \multirow[b]{2}{*}{ Cover } & \multirow{2}{*}{$\begin{array}{l}\text { Aluminum } \\
\text { Alloy }\end{array}$} & \multirow{2}{*}{5000} & Spinning & \begin{tabular}{|l} 
High labor costs \\
Low production rates \\
Limited detail and accuracy
\end{tabular} & 1.8 \\
\hline & & & Deep Drawing & \begin{tabular}{|l|} 
Low labor costs \\
High production rates \\
High detail and accuracy \\
\end{tabular} & 1 \\
\hline \multirow{2}{*}{ Connecting Rod (afte } & \multirow{2}{*}{$\begin{array}{l}\text { Medium Carbon } \\
\text { Steel }\end{array}$} & \multirow{2}{*}{100000} & $\begin{array}{l}\text { Closed } \\
\text { Die Forging }\end{array}$ & $\begin{array}{l}\text { Long lead times } \\
\text { High tooling costs } \\
\text { High equipment costs }\end{array}$ & 1.3 \\
\hline & & & Sand Casting & $\begin{array}{l}\text { Short lead times } \\
\text { Low tooling costs } \\
\text { Low equipment costs }\end{array}$ & 1 \\
\hline \multirow{2}{*}{ Pump Gear } & \multirow{2}{*}{$\begin{array}{l}\text { Low } \\
\text { Carbon } \\
\text { Steel }\end{array}$} & \multirow{2}{*}{5000} & Machining & $\begin{array}{l}\text { High waste } \\
\text { Low to medium production rates } \\
\text { Poor strength }\end{array}$ & 2.6 \\
\hline & & & Cold Extrusion & $\begin{array}{l}\text { Little waste } \\
\text { Very high production rates } \\
\text { High strength }\end{array}$ & 1 \\
\hline
\end{tabular}

\section{IMPORTANCE OF SELECTION PRIMARY PROCESS IN PROCESS PLANNING}

Process planning [1-3] is essential in production preparation process because it defines processing parameters, machine tools, cutting tools, production times, and production costs. These data are useful for technological improvement and management of production costs. Process planning provides basic data for the production designer because these data define the distribution of jobs for the 
realization of orders and delivery times. The primary process has a significant influence on after-treatment processing time, the machine occupancy, the production cost, and the delivery period.

Tab. 1 provides examples of how different shapes, materials, number of pieces, relative production time, and the manufacturing process affect the production costs. The key fact is that the observed product is a shaft that must be resistant to twisting and bending stresses. Data sources according to Halevi [1], ASM Handbook [4] and SwiftBooker [5] were used to help select the primary process [35].

\section{DECISION SUPPORT THROUGH MULTI-CRITERIA OPTIMIZATION}

Decision support systems are based on artificial intelligence and strive for an optimal solution (so-called multi-criteria optimization). In a single-objective optimization, with objective function and constraints, a solution is relatively easy to find.

But a real situation, in most cases, requires multi-criterial optimization. This results in the necessary compromises if the criteria are conflicted (for example, one criterion increases the observed variable, the other reduces it). This necessarily indicates the expected subjectivity of the decision-making support, since the assessment of the "criterion strength" is the result of the experience, knowledge and intuition of the experts in the considered field. The expected subjectivity is being somewhat reduced by team building and brainstorming of more experts.

\subsection{Analytic Hierarchical Process (AHP method)}

AHP first enables interactive structuring (hierarchy formatting) of problems to prepare decision-making scenarios. A hierarchically structured decision-making model consists of a goal, criteria, several possible levels of sub-criteria and alternatives. The goal is always at the top and it cannot be compared with any other element. The AHP method is not the only method, there are also the Electre and the Promethee methods.

Analytical hierarchical process (AHP) is solved in four phases [6-9]:

1) Structuring the problem

2) Determining the most important criterion

3) Determining the most significant alternative

4) Determining the final solutions (goal).

\section{EXPERT CHOICE SOFTWARE}

The Expert Choice software is used to solve semistructured and unstructured decision-making problems. It is based on the AHP [7] method, and Tomas Saaty $[6,8]$, an author of the AHP method, participated in its development. The idea is that the assessment of the importance of criteria and sub-criteria, as well as the assessment of the importance of alternatives in relation to the criteria, is carried out by the decision-maker. This allows the method to better cover all subjective views and objectives used by the decision-maker.

\subsection{Consistency}

The consistency of the whole process is checked through a consistency index, which must be less than $10 \%$ in order to make a decision that can be accepted as valid and consistent. Consistency means the consistency of decision makers in their decisions and assessments [6].

\section{CASE STUDY OF PRIMARY PROCESS SELECTION}

At first, the primary process is selected according to Halevi, then by the ASM Handbook and finally by SwiftBooker $[1,4,5]$. The eccentric effect of the considered shaft influences the process of selecting the primary process and subsequent processing.

\subsection{Process Selection in Process Planning}

The defined forging has a symmetry axis; the shape is a shaft (Fig. 1) with different cross-sections. The length of the forging is greater than its width. Influential factors are the asymmetric part, the outer and inner threads at the ends, the slots to be milled and the relatively large L/D ratio.

Product features:

- Material: St 44-2 - unalloyed steel or E275 (1.0225)

- Weight: $19.24 \mathrm{~kg}$

- Minimum wall thickness: $15 \mathrm{~mm}$

- Cam length: $124 \mathrm{~mm}$

- Hole length: $205 \mathrm{~mm}$

- Maximum diameter: $\varnothing 123 \mathrm{~mm}$

- Most demanding surface quality: $R a 0.4$ (other $R a 1.6$ and $R a 6.3$ )

Thought guides for 120000 pieces are:

1) Less influence of the executors,

2) More uniform quality,

3) The production should be as short as possible,

4) More precise processing,

5) No measurements before processing for each workpiece.

The hierarchical structure (Fig. 2) is designed to determine the optimal primary process through multi-criteria decision making. When using the AHP method, the basic and functional properties of the workpiece were considered. Closed die forging has no alternatives; the only variant is precise forging that is not considered. In the observed shaft, the eccentric part of geometry causes a problem when choosing the primary process, and later when the machining process takes place.

Fig. 2 shows the hierarchical structure of the problem introduced with the final goal and defined criteria and subcriteria. 


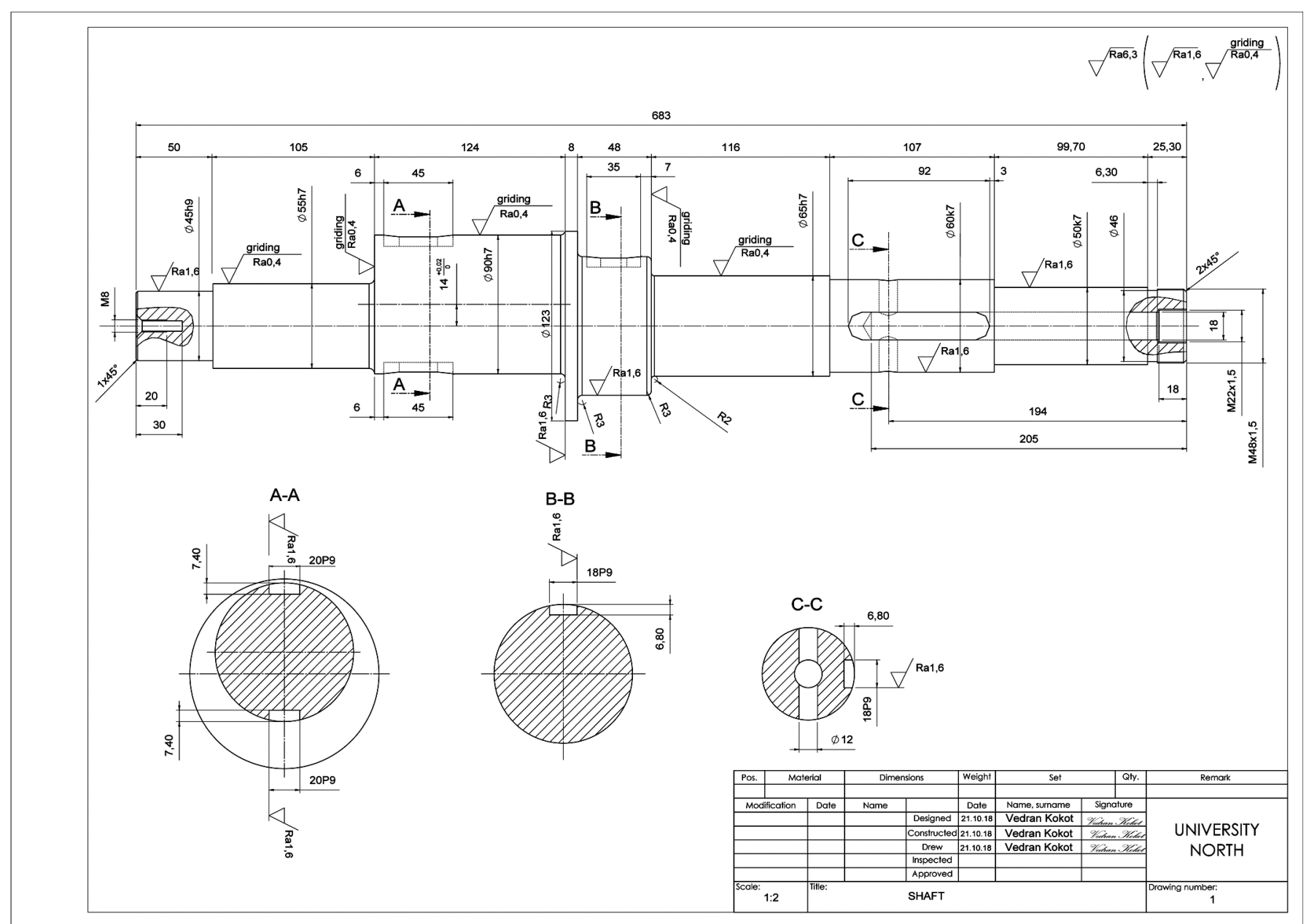

Figure 1 Technical drawing of a final part

\subsubsection{Halevi's Primary Process Selection}

The first step of primary process determination, according to Halevi [1], is to define the workpiece complexity. Therefore, the most similar shape is selected in Fig. 3. As with any general solution, it must be noticed that there are too few forms offered, making the choice more difficult and therefore less precise. The second step is, based on the selected shape and quantity, to weight primary process technology that is suggested, from best to worst (Fig. 3). The interval boundaries are tightly set. For non-existent intervals the designer can search for the solution from the nearest interval.

The boundaries between intervals are not set and this is the biggest problem when selecting the primary process according to Halevi. In addition, the problematic fact is that the influence of the material type is not initially taken as a factor according Halevi. By comparing the basic offered forms with the product form that we have, it is concluded that it is an open form with a variable cross-section along the axis. After selecting the shape type, it is necessary to select one of the production processes that can be seen in Fig. 3 .

The primary processes are as follows (Fig. 3):

A - Casting process

$\mathrm{B}$ - Metal forming process

$\mathrm{C}-$ Cutting (machining) process

$\mathrm{D}$ - Joining process

E - Mounting process

$\mathrm{F}$ - Magnifying process.

Fig. 3 displays the product shape type. For the quantity of 120000 pieces, it is suggested to choose the processing type $B$ - metal forming. 


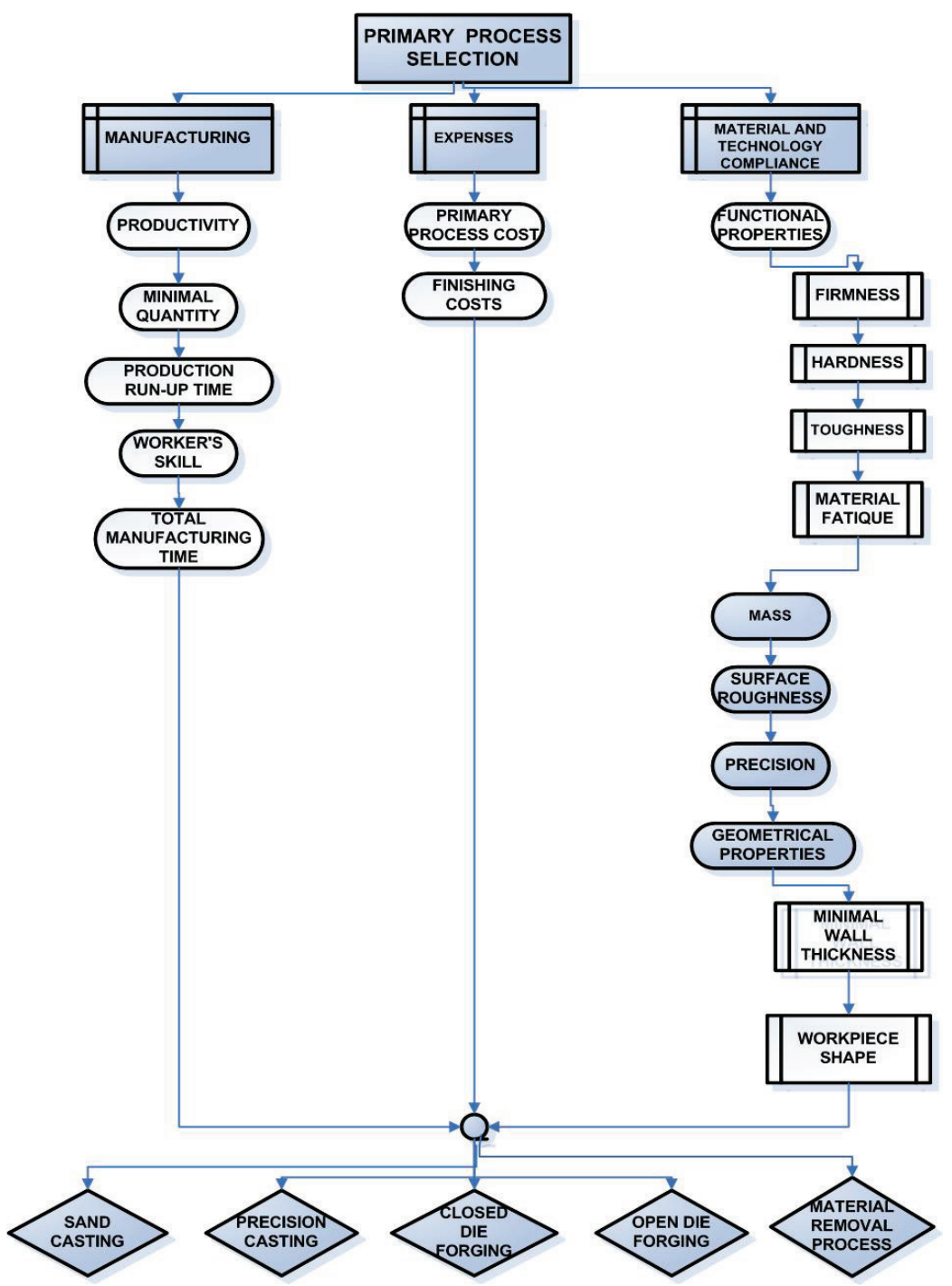

Figure 2 Hierarchical structure selection of the primary process

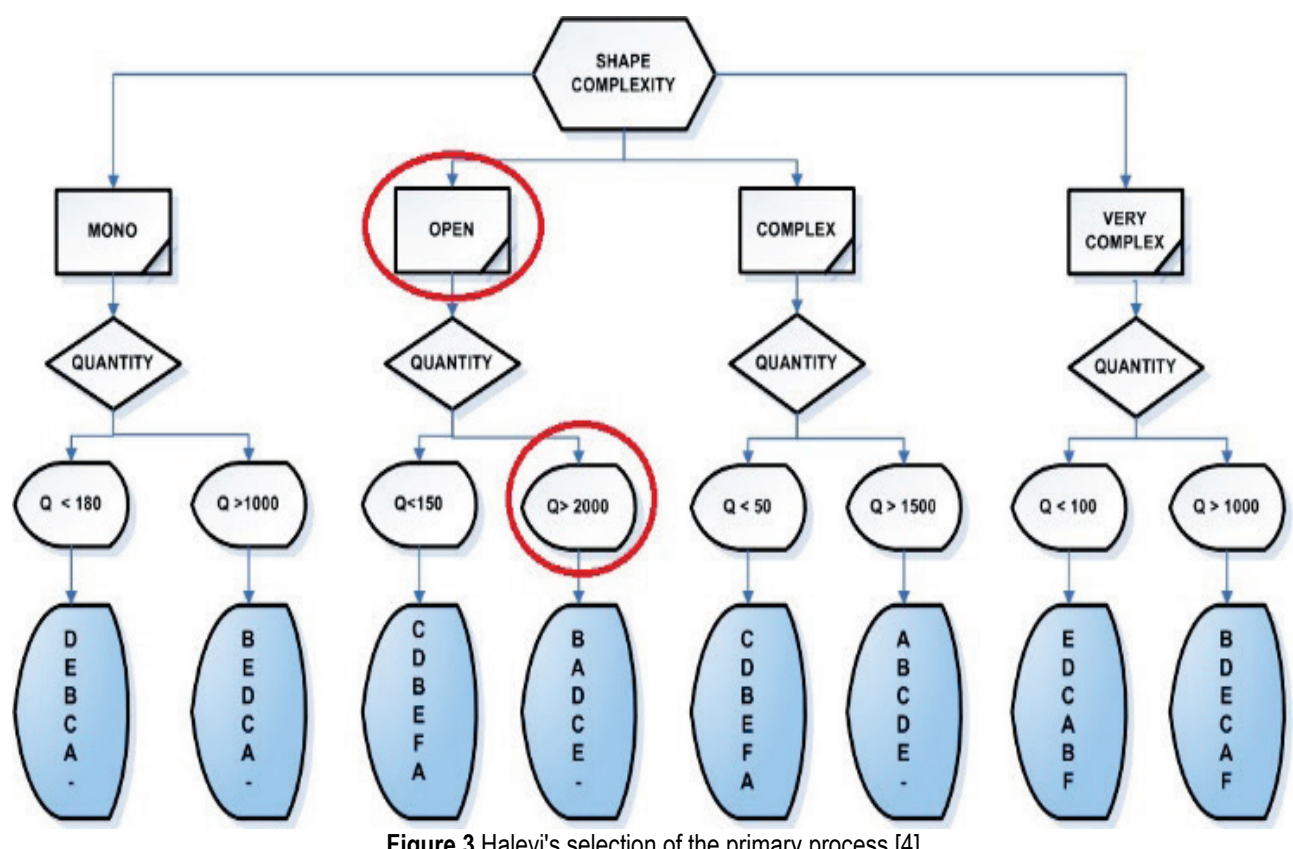

Figure 3 Halevi's selection of the primary process [4] 


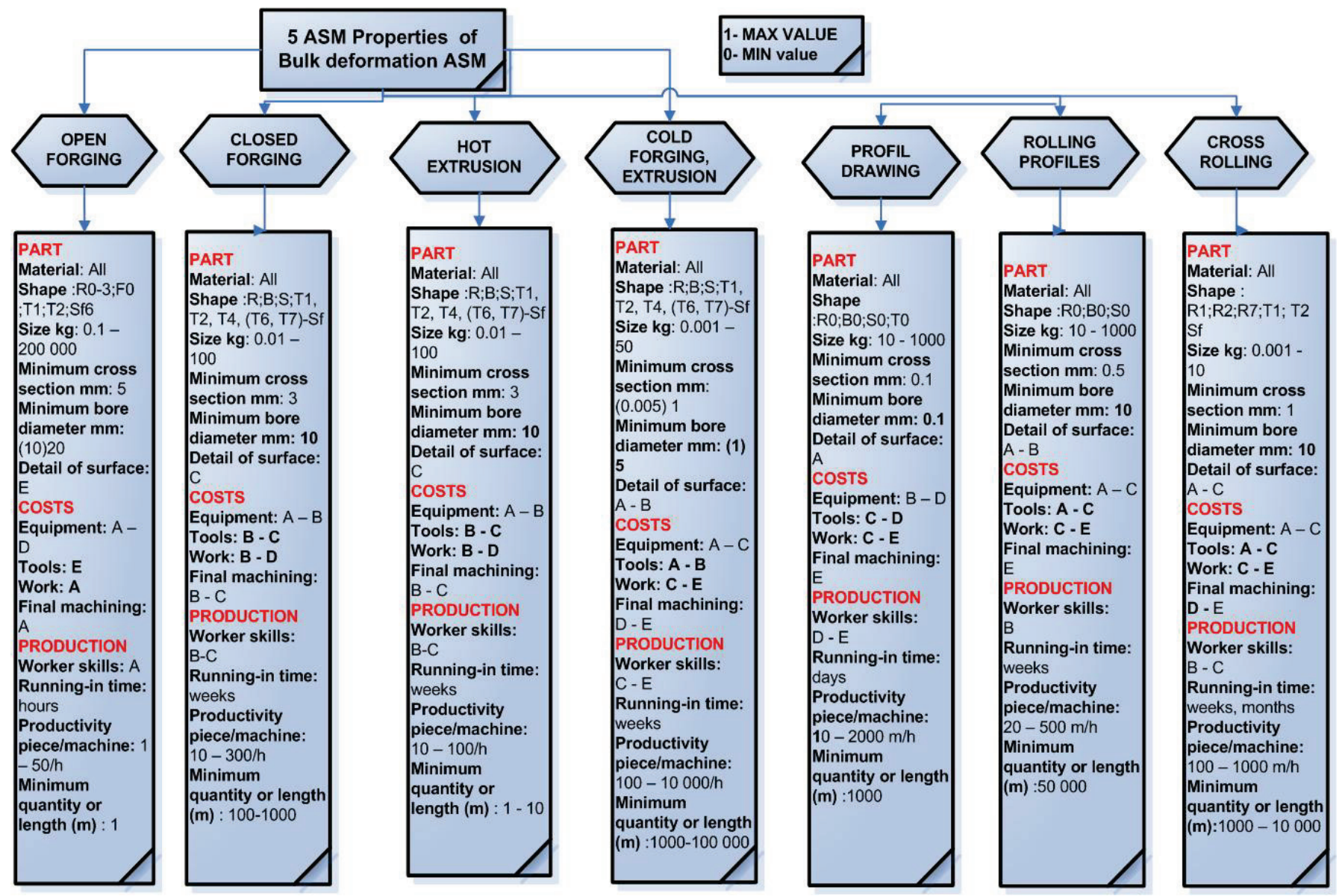

Figure 4 ASM's selection of the primary process [4]

\subsubsection{ASM's Primary Process Selection}

The first step of the primary process determination, by ASM [4], is to select possible primary process technologies (Fig. 4) only based on the type of material. The second step is to determine the type of the shape complexity of the desired product. The conclusion is that it is a complex form with a round cross-section. In this step, there is a "type of gap" because there is no logical step sequence how to narrow down the choice of offered technologies, after selecting possible technologies and choosing shapes. According to the ASM handbook, there is a "gap" to be "filled" by the intuition and knowledge of the technologist because the process of narrowing down potential primary process procedures is not defined. When defining metal forming process by ASM, attributable features of the finished piece are applied (Fig. 4); they are highly subjective and can have major influence on the final selection. Thus, someone's experience here comes to the fore by introducing the criterion of functionality.

\subsubsection{Swift-Booker's Primary Process Selection}

The starting point is a table in Fig. 5. It provides information that the primary process, closed die forging, is economically viable for a combination of material and production quantity. Tab. 2 defines the dimensions of the forging diameter calculated according to reference [10]. The applied couture angles $\left(5^{\circ}-7^{\circ}\right)$ serve the purpose of easy ejection from the die (in hammer forging process), without special ejector pin.

\section{CLOSED DIE FORGING PROCESS CAPABILITY CHART FOR LOW TO MEDIUM CARBON AND LOW ALLOY STEELS (WEIGHT 10 TO 50 KG)}

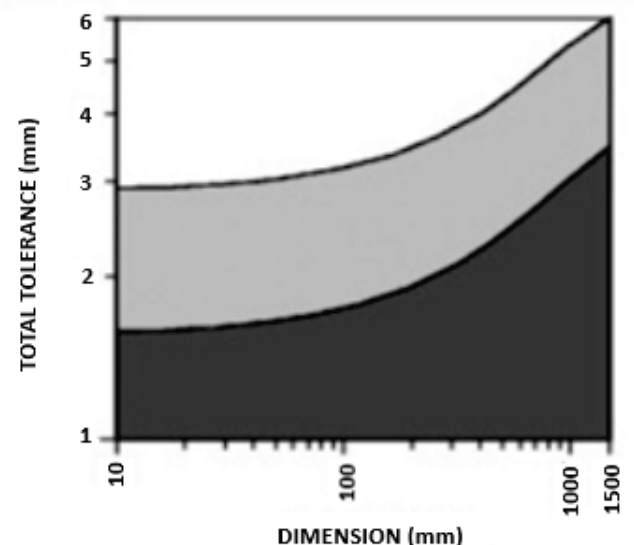

Figure 5 Features of closed die forging process capability [3]

By comparing calculated tolerances (Tab. 2) and process capability diagrams (Fig. 5), we see that closed die forging 
represents a normal working ability, in the diagram presented in a light grey area.

The dimension adding in forging can be reduced from 7 $\mathrm{mm}$ (according to [10]) to $4 \mathrm{~mm}$ because of technology modernization. This option would significantly shorten the cutting process on the CNC machine. What is imposed as an obstacle in reducing the dimension adding is that this can lead to the strain appearance in workpiece due to the activity of horizontal forces (excenter), so the quality of the product itself will be questionable.

Table 2 Spreadsheet of processing features (diameters) and tolerances

\begin{tabular}{|c|c|c|c|c|c|c|c|c|c|c|c|}
\hline Determination of dimension $D$ & $\varnothing 45$ & $\varnothing 55$ & $\varnothing 90$ & $\varnothing 123$ & $\varnothing 90$ & $\varnothing 65$ & $\varnothing 60$ & $\varnothing 50$ & $\varnothing 48$ \\
\hline \multicolumn{2}{|c|}{ Quality of processing } & $\Delta 2$ & $\Delta 2$ & $\Delta 2$ & $\Delta 2$ & $\Delta 2$ & $\Delta 2$ & $\Delta 2$ & $\Delta 2$ & $\Delta 2$ \\
\hline \multicolumn{2}{|c|}{ Processing allowance $\delta / 2$} & 3.5 & 3.25 & 3.25 & 3.5 & 3.5 & 3.25 & 3.5 & 3.5 & 3.5 \\
\hline \multicolumn{2}{|c|}{$D_{\mathrm{k}}=D+\delta$} & 52 & 61.5 & 96.5 & 130 & 97 & 71.5 & 67 & 57 & 55 \\
\hline \multicolumn{2}{|c|}{$D_{\mathrm{k}}$ (rounded) } & $\Delta c$ & 0.1 & 0.24 & 0.24 & 0.36 & 0.24 & 0.24 & 0.24 & 0.24 & 0.1 \\
\hline \multirow{2}{*}{ Tolerances } & $x$ & 2.37 & 2.27 & 2.51 & 2.63 & 2.51 & 2.51 & 2.51 & 2.51 & 2.37 \\
\cline { 2 - 32 } & $y$ & 1.16 & 1.3 & 1.3 & 1.42 & 1.3 & 1.3 & 1.3 & 1.3 & 1.16 \\
\hline
\end{tabular}

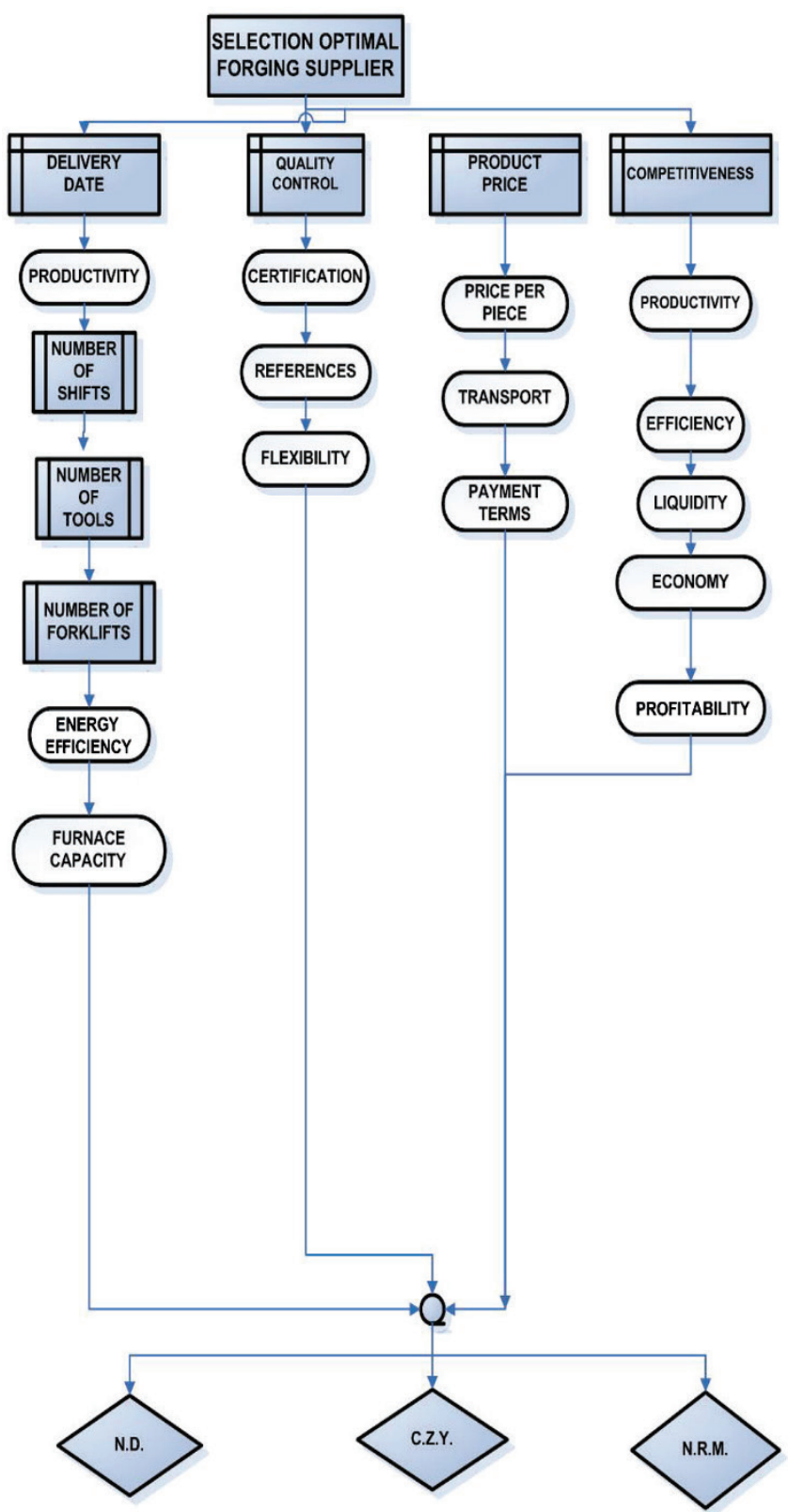

Figure 6 Hierarchical structure selection of suppliers

\subsection{Selection of Optimal Supplier}

For the default workpiece, the optimal forging offer should be selected according to defined criteria. The offer request has been sent and three offers have been received from China that differ in delivery time, price and quality. The production and delivery of 120000 pieces of the final product were considered. Several data should have been assumed because they represent a technological and trade secret, for example, hourly labor costs, hourly machine costs, productivity, efficiency, liquidity and profitability. It is therefore important to highlight the subjectivity when assessing the weights of sub-criteria and criteria. Fig. 6 shows the hierarchical structure of the criteria and subcriteria with the goal of selecting the forging offer.

The competitiveness criteria with sub-criteria productivity, efficiency, liquidity, economy and profitability - are set as a reason why. It was not possible, for the purposes of the previous project, to obtain such exact data concerning the business of the considered forging companies.

\subsubsection{Delivery Date}

Because of a large series, it is primarily necessary to concentrate on the short delivery period in order to make the entire production cycle as short as possible. This means that the default production forging process must be done in a short period, so the first container shipment could arrive as soon as possible. The forging time and the transport from China, first by boat and later by truck, are related to the production time, which means that if it is possible to shorten the time of forging and transport, the price will be reduced. As the number is 120000 pieces, time saving can be expected. The delivery time will be improved so that the cutting (CNC machining) starts immediately after the pick-up of the first container shipped from China. This means that the operator of the CNC machine will begin the preparation of the numerically operated machine one month after the first shipment from China is sent. In this way, the production cycle, i.e. delivery deadlines, and thus the occupancy of a high-speed and high-productive $\mathrm{CNC}$ processing center, are shortened. In addition, further production planning is 
possible, thus achieving greater competitiveness in the market.

\subsubsection{Productivity}

Productivity is affected by the following:

- number of working shifts,

- number of machines and number of forging tools,

- number of forklifts and number of employees.

The level of automation and the number of robots in the production reduce the time needed to introduce the new model and reduce the time and material loss. Of course, the questions that do not have answers in $[3,4]$ still remain: What type of heating to choose (flame furnace, induction heating); What type of machines to choose (bat, press); What kind of forging die design to choose - how many engravings in one die; How many forgings (according to the size and mass) can be forged at the same time? According to [4], which uses the practical research and experience, the mass adding for die filling insurance increases both the mass of the workpiece, the price of the material, and the cost of heating for the material which is later removed as a waste.

\subsubsection{Quality Control}

The elimination of the strain in the forging workpiece due to the appearance of horizontal forces could be avoided by forging two forgings in one forging die, which would halve the forging time, and the quality would be higher. But these factories do not have such large forging machines or dies for the expected dimensions of the default shaft. It should be emphasized that the simultaneous forging of two workpieces depends on the mass of drop-down parts of forging hammers. The offer states that additional product control that improves quality and productivity reduces risk and ensures fast shipping. A SGS control provides solutions involving control, certification, auditing and verification. SGS is a Geneva-based multinational company that also ensures that products, systems or services meet the requirements set by SGS customers. An internal audit of the company submits a daily production report to the client.

\subsubsection{Certification}

The market competition is serious, and the buyer has the choice. The tenders require additional quality assurance to reduce the cost of input control and reduce the risk of substandard purchases. Additional warranty includes ISO certificates 9001, 20001 and 14001. The forging factories N.R.M. and N.D. claim that they have the three mentioned certificates, while the forge of C.Z.Y. is certified by IATF 16949. It is not possible to know whether these forges implement quality systems because deeper analysis is not done.

\subsubsection{References}

Looking at the process of forging and acquiring from China, from an organizational point of view, all parts of the business are well considered and planned, as evidenced by the fact of long-term cooperation on the global level with many world-famous companies. The most significant external clients of the forge factory N.D. are "McLaren" and "Subitomo Rubber". The clients of the forge factory C.Z.Y. are "Bosch", "Volvo" and "Scania", while the most famous references of the forge factory N.R.M. are "CCL UK" and "HMI USA". Of course, it is not possible to compare which company is "more present" in the market because there is no information available on which products they produced for them, so there is a certain subjectivity when giving importance to references. Important criteria for such a business are the success of the arrangement, compliance of the delivery time and quality of production, flexibility and adaptability to changes in the arrangement. Further organizational improvements concern production directly and further processing of ordered forgings.

\subsubsection{Product Price}

Since the big series is concerned, a small price difference of a few dollars (USD dollar) per piece (forging) means a big difference of several hundred thousand dollars of the total forging price. A big role in the price is played by the exchange rate which varies and which of the currencies of USD/HRK, EUR/HRK, USD/EUR are calculated. In the offers, the exchange rate was calculated in USD compared to the Chinese RMB (YUAN) from the PBOC ("People's Bank of China") and the exchange rate was 6.8 with the date of December 28, 2018. The shipping price of the container from China is not the same for every month of the year. At the beginning of the year (i.e. January 2019), the fares are at a much higher level than for the rest of the year; this especially applies to containers with dimensions of 40' (inches), which were about $\$ 200-500$ cheaper during the last year.

\subsubsection{Payment Terms}

The payment method is $30 \%$ in advance, and the other $70 \%$ in cash on delivery as required by the forge factories C.Z.Y. and N.R.M., while the forge factory N.D. requires paying $50 \%$ in advance and the other $50 \%$ on delivery. However, they are open to negotiations and explain that if a long-term relationship is established, the terms of payment can be discussed.

\section{ANALYSIS OF RESULTS}

Based on the set of criteria and the alternatives, the decision is to be made. By using the AHP method, it is necessary to decide about the selection of the forging offer. As explained earlier in Chapter 5, when weighting individual criteria, the most important criterion is the delivery time when choosing the optimal primary process. The deadline 
should be shortened in order to shorten the entire production cycle.

The forge factory comparison (Tab. 3) was used to simplify the entry and display of data in Expert Choice.

The results show that the best choice is the forge factory N.R.M., where the priority vector has the highest value, although the remaining two forge factories do not fall far behind. The second choice is the N.D. and the third is C.Z.Y., which is also shown in Fig. 7.

\begin{tabular}{|c|c|c|c|} 
Table 3 Comparison of three forges \\
\hline Forges & N. D. & C. Z. Y. & N. R. M. \\
\hline Delivery time & 3 months & 10 months & 12 months \\
\hline Productivity per day & 1333 forgings & 600 forgings & 455 forgings \\
\hline Productivity per worker per day & 8 forgings & 17 forgings & 4 forgings \\
\hline Price per piece & $40.5 \$$ & $52.11 \$$ & $35.17 \$$ \\
\hline Mold for price & $6,618 \$$ & $22,332 \$$ & $5,880 \$$ \\
\hline Total price $(120000$ pcs.) & $4,860,000 \$$ & $6,253,200 \$$ & $4,220,400 \$$ \\
\hline Payment terms & $\begin{array}{c}50 \% \text { in advance, the } \\
\text { balance is paid on } \\
\text { delivery }\end{array}$ & $\begin{array}{c}30 \% \text { in advance, the } \\
\text { balance is paid on } \\
\text { delivery }\end{array}$ & $\begin{array}{c}30 \% \text { in advance, the } \\
\text { balance is paid on } \\
\text { delivery }\end{array}$ \\
\hline Certification & ISO 9001,20000 & IATF 16949 & ISO 9001,14001 \\
\hline References & McLaren, Subitomo & Bosch, Volvo & CCL UK, HMI USA \\
\hline Number of shifts & Two nine-hour shifts & One twelve-hour shift & One ten-hour shift \\
\hline Number of employees & 150 & 35 & 120 \\
\hline Number of forklifts & 6 & 1 & 6 \\
\hline Number of forging machines & 12 & 3 & 1 \\
\hline Type of heating in furnaces & Electric heating & Electric heating & Induction heating \\
\hline
\end{tabular}

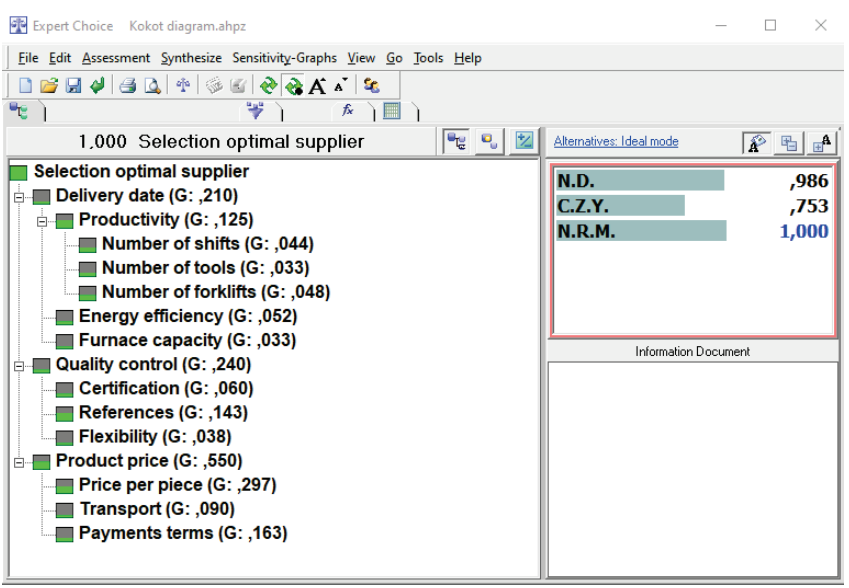

Figure 7 Model view of the results obtained by Expert Choice

Hes Facilitator: Peffomance Sensitivity for nodes below -- Selection optimal supplier

File Options Tools Window

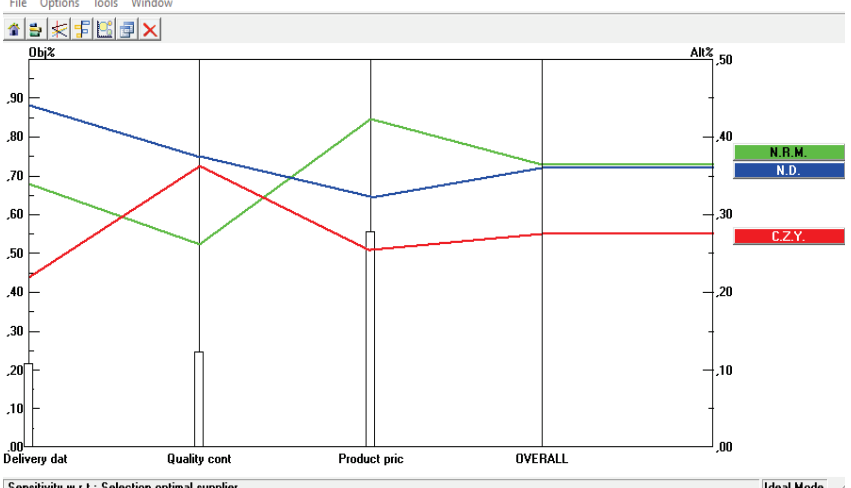

Figure 8 Diagram of the results obtained by Expert Choice
Graphic analysis (Fig. 8) clearly shows that forge N.D. is the best alternative. The result was expected as the delivery time is the most important criterion.

If the relation between the criteria were changed, i.e. if the price of the product was the most important criterion, different results would be generated as shown by Fig. 9 .

The graphic analysis of the changed relations (Fig. 10) clearly shows that the forge factory N.D. is the best alternative. It was obtained when the price of the product was set as the most important criterion.

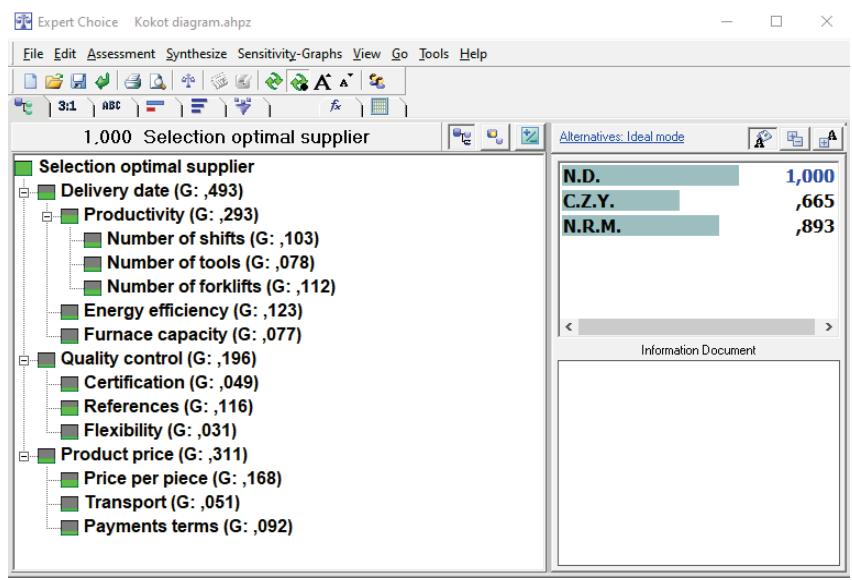

Figure 9 Model view of the results obtained by changed criteria

Les Facilitator: Pefformance Sensitivity for nodes below -. Selection optimal supplies

File Options Tools Window

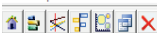

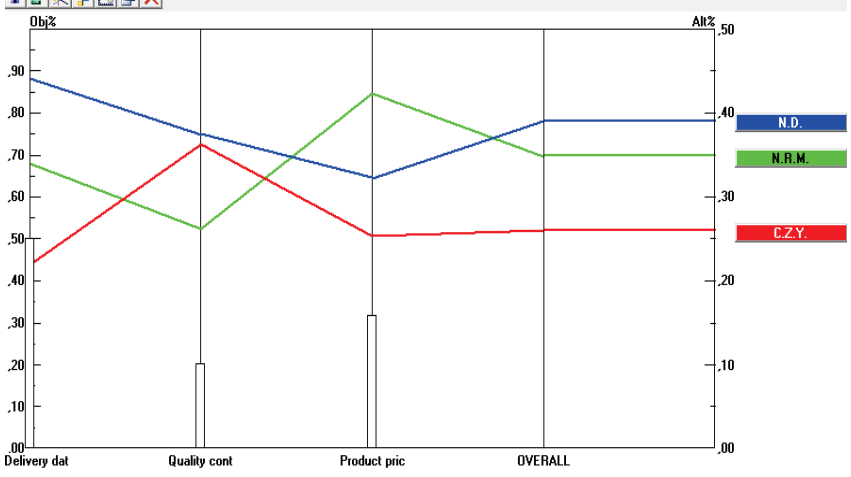

Senstivity w.t.: Selection optinal supplier
Figure 10 Diagram of the results obtained by changed criteria

\section{CONCLUSION}

The implementation of the AHP method was performed for a concrete shaft workpiece, using Expert Choice 11. Based on the analysis of the results, the relation between each one of the weighted criteria affects the goal of selecting the optimal forging supplier. Three criteria that have an intense impact on selection have been analyzed, especially the delivery time and product price. The results show that the optimal forge factory is N.D. The specified forge is the best according to the following criteria: delivery time and quality management. This choice is logical since the delivery criterion is the most important. It is explained that the competitiveness criterion also affects the selection of the optimal provider, but due to the unavailability of the data, it 
was not considered in the analysis of the results. The subjectivity of the decision-maker has a great impact on the result. The preparation of the business environment itself and the insight into the business process of the three forge factories, between which the selection was carried out, is very important. Thus, if the cooperation with Chinese forge factories had been longer and deeper, more exact data would have been obtained, such as rejects percentage, product return, productivity, efficiency, economy, liquidity, profitability, etc. If these data had been known, the criteria would have been differently evaluated, and they would certainly influence the final decision. It would be interesting to compare, according to presented criteria, the difference between precise forging and closed die forging.

\section{Notice}

The paper was presented at MOTSP 2020 - International Conference Management of Technology - Step to Sustainable Production, which took place from $30^{\text {th }}$ September $-2^{\text {nd }}$ October 2020 in Bol, island Brač (Croatia). The paper is not and will not be published anywhere else.

\section{REFERENCES}

[1] Adithan, M. (2007). Process Planning and Cost Estimation, New Age International (p) Limited, Publishers, New Delhi.

[2] Slack, N., Chambers, S., Johnston, R., \& Betts, A. (2009). Operations and Process Management, 2nd edition, FT Prentice Hall, Harlow.

[3] Swift, K. G. \& Booker, J. (2003). Process Selection: From Design to Manufacture. Second Edition. Process Selection: From Design to Manufacture: Second Edition. 1-316. https://doi.org/10.1016/B978-075065437-1/50000-7

[4] Halevi, G. (2003). Process and Operation Planning: Revised Edition of the Principles of Process Planning: A Logical Approach, Kluwer Academic Publishers.

[5] Davis, J. R., Semiatin, S. L. et al. (1989). ASM Metals, Handbook, Vol. 14: Forming and Forging, $9^{\text {th }}$ edition (\#06360G).

[6] Saaty, T. L. (2008). Decision making with the analytic hierarchy process. Int. J. Services Sciences, 1(1), 83-98. https://doi.org/10.1504/IJSSCI.2008.017590

[7] Coyle, G. (2004). Practical Strategy. Open Access Material. AHP The Analytic Hierarchy Process (AHP).

[8] Saaty, T. L \& Vargas, L. G. (2012). Models, Methods, Concepts \& Applications of the Analytic Hierarchy Process, Springer, New York. https://doi.org/10.1007/978-1-4614-3597-6

[9] Clemen, R. T. (1996). Making Hard Decisions, An Introduction to Decision Analysis, $2^{\text {nd }}$ Edition, Fuqua School of Business, Duxbury Press.

[10] Musafija, B. (1988). Obrada metala plastičnom deformacijom. Svjetlost, Sarajevo. (in Bosnian)
Authors' contacts:

Predrag Ćosić, PhD, Full Professor

(Corresponding author)

University of Zagreb,

Faculty of Mechanical Engineering and Naval Architecture, Ivana Lučića 5, 10000 Zagreb, Croatia

38591413 1450, e-mail: pcosic3@gmail.com

Zdenka Keran, PhD, Assistant Professor

University of Zagreb,

Faculty of Mechanical Engineering and Naval Architecture, Ivana Lučića 5, Zagreb, Croatia

e-mail: zdenka.keran@motsp.eu

Vedran Kokot, BSc, student of Master Study University North,

Jurja Križanića 31b, 42000 Varaždin, Croatia

e-mail: vekokot@unin.hr 